\title{
CHRONIQUE
}

\section{Deuxième Congrès international des Oeuvres de secours aux enfants des pays éprouvés par la guerre.}

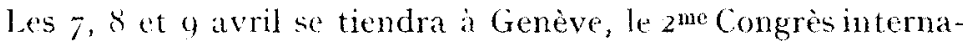
tional des ceuvres de sccours aux enfants des pays éprouvés par la guerre. On se souvient que le I er Congrès a eu lieu l'année passée, en février, à l'hôtel des Bergues, et que l'affuence y fut grande. Près de 200 persomes, parmi lesquelles on comptait de hauts dignitaires de toutes les Eglises, prélats catholiques et évêques anglicans, des représentants qualifiés des grandes institutions de secours, américains et anglais, et des comités d'hospitalisation, suédois, norvégicns, danois, suisses, etc., des socialistes, des délégués de I5 Croix-Rouges, se sont réparties en une douzaine de commissions distinctes pour étudier dans chacun des pays les plus éprouvés, la situation des malheureux enfants. En trois jours, un travail considérable fut effectué : 25 rapports imprimés furent distribués et commentés, et un tableau de la détresse des enfants et de leurs besoins put être tracé à grands traits.

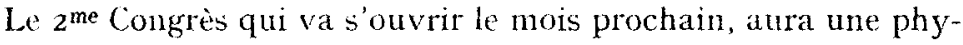
sionomie toute différente. Plus de commissions nationales pour étudier la situation de chaque pays, cette situation pouvant être considérée aujourd'hui comme suffisamment connue grâce à l'abondante documentation recueillie pendant le cours de l'année par l'Union internationale de Secours aux enfants et résumée dans les foo pages de son Bulletin. l.ordre du jour ne prévoit que des séances plénières où seront débattues trois questions générales : les méthodes de secours: la coordination des efforts et le problème des réfugiés russes.

L'étude des méthodes de secours comprendra: l'alimentation des enfants, entretien total suivant le système des adoptions qui se développe de plus en plus, mais ne peut être appliqué qu'à un petit nombre d'enfants; entretien partiel tel que les repas scolaires distribués par la grande action américaine de $M$. Herbert 


\section{CHRONIQUE}

\section{Secours aux enfants.}

Hoover, laquelle vient en aide à $3 \frac{1}{1 / 2}$ millions d'enfants. En ce qu concerne l'habillement, le Congrès abordera la question des ouvroirs, méthode qui tend à se généraliser en raison de son double avantage de fournir du travail rémunéré aux mères et des vêtements aux enfants. Les secours médicaux, lutte contro la tuberculose (sanatoriums, préventoriums), dispensaires pour nourrissons, athrepsie, clôtureront cette première partie.

La $2^{\text {me }}$ partie, coordination des efforts, permettra d'établir la comparaison entre le rendement des ceuvres nationales (gouvernementales ou privées) et des œuvres étrangères. La coordination de ces œuvres est, depuis longtemps, la préoccupation principale de l'Union internationale de Secours aux enfants. Dans ce domaine, elle a trouvé un puissant appui dans le Comité international de la Croix-Rouge, dont les délégations lancées comme deantennes vers les points les plus sensibles de l'Europe éprouvée. s'efforce d'établir sur place la liaison entre tant d'œuvres en activité, à Varsovie, Vienne, Budapest, Riga, Constantinople, etc. Plus de ro délégations du Comité international de la Croix-Rouge ont fourni à l'Union internationale des rapports circonstanciés sur leur activité : convocation de réunions périodiques des auvre: de secours, enquêtes sur les besoins des enfants, contrôle des distributions, etc. La Ligue des Sociétés de la Croix-Rouge a offert récemment à l'Union internationale de Secours aux enfants, le concours de ses délégués. Déjà une première mission en Yougoslavie a rapporté des données intéressantes; une mission qu vient de partir en Tchécoslovaquie rassemblera sans doute aussi des documents. L'Union internationale qui a réussi à intéresser à l'enfance malheureuse, les Eglises de toute confession, les congrès féministes, socialistes, ctc., les Sociétés de la Croix-Rougt, compte, à l'heure actuelle, ro comités collecteurs nationaux, qui lui envoicnt le pourcentage de leurs recettes comme fonds de premier secours. Dans le courant de l'année I920, les association: affiliées à l'Union internationale n'ont pas distribué moins de 26 millions de francs suisses. A Genève même, le Comité exécutif de l'Union, ne disposant que du pourcentage auquel il a été fait allusion, a distribué plus de I million de francs suisses. Ou'il 


\section{CHRONIQUE \\ Secours aux enfants.}

ait été versé par des mains catholiques, protestantes, orthodoxes, israélites, qu'il rienne de l'accumulation, sou par sou, de collecues dans les milieux ouvriers, l'argent ainsi recueilli a contribué grandement au soulagement de l'enfance malheureuse. Mais ces sommes, si considérables qu'elles apparaissent, restent encore très inférieures à celles que M. Herbert Hoover a su trouver 'n Amérique, où son dernier appel lui a fait obtenir 33 millions de dollars. L'Union internationale travaille en liaison étroite avec la grande action américaine, à Budapest notamment, comme avec la Croix-Rouge américaine, qui au moyen des cotisations de ses 9 millions d'écoliers américains, a multiplié en Europe les missions de secours.

La coordination des efforts est donc déjà en bonne voie, et sa réalisation sur place devient de jour en jour plus effective.

La dernière question abordée par le Congrès sera celle des réfugiés russes. On sait tout l'intérêt qui s'attache à ces malheureux réfugiés, au nombre de I million disent les uns, de 2 millions disent les autres, disséminés dans les divers Etats de l'Europe depuis la mer Blanche jusqu'à la Méditerranée. L'Union internationale dépense en ce moment une centaine de mille livres sterling en faveur de ces malheureux, et elle envisage de faire porter son effort principal au cours de l'année I921, en faveur de leurs enfants. Elle est assurée dès à présent du concours de l'American Relief Administration et de la Croix-Rouge Américaine. Ces actions de secours travailleront en liaison étroite avec les autres associations charitables des réfugiés adultes.

Les inscriptions au Congrès sont reçues au siège de l'Union internationale de Secours aux enfants, 4 rue Massot, Genève.

E. C. 


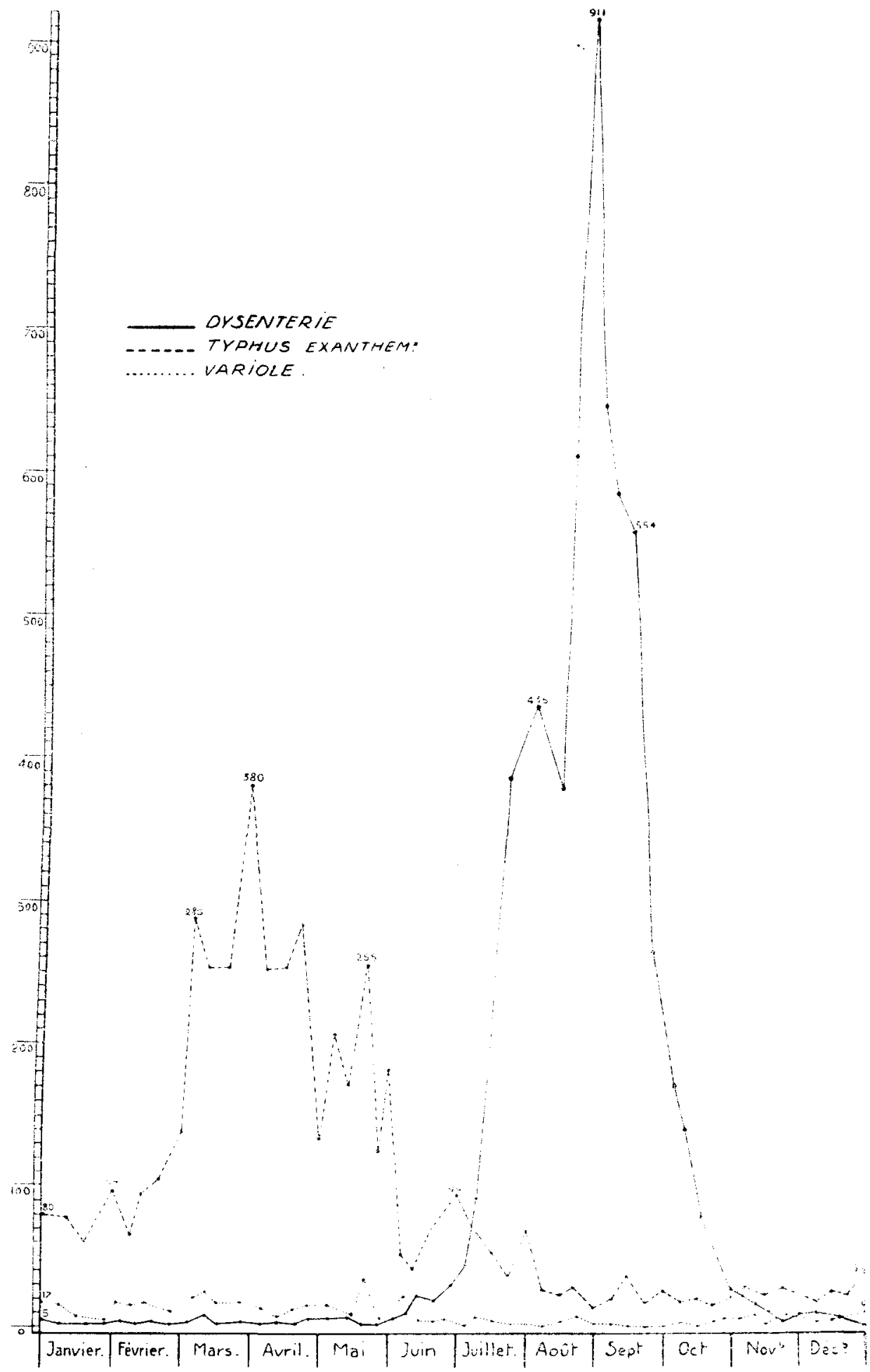

Graphique des maladies épidémiques en Latvia en 1920. 